\title{
Исследование вольт-амперных характеристик светодиодных гетероструктур на основе InAsSb в диапазоне температур $4.2-300 \mathrm{~K}$
}

\author{
(C) А.А. Семакова ${ }^{1}$, Н.Л. Баженов ${ }^{2}$, К.Д. Мынбаев ${ }^{2}$, А.В. Черняев ${ }^{2,3,4}$, С.С. Кижаев ${ }^{3}$, Н.Д. Стоянов ${ }^{3}$ \\ ${ }^{1}$ Университет ИТМО, \\ 197101 Санкт-Петербург, Россия \\ 2 Физико-технический институт им. А.Ф. Иоффре Российской академии наук, \\ 194021 Санкт-Петербург, Россия \\ ${ }^{3}$ Микросенсор Технолоджи, \\ 194223 Санкт-Петербург, Россия \\ ${ }^{4}$ Военная академия связи им. С.М. Буденного, \\ 194064 Санкт-Петербург, Россия \\ E-mail: antonina.semakova@itmo.ru
}

Поступила в Редакцию 28 января 2021 г.

В окончательной редакции 3 февраля 2021 г.

Принята к публикации 3 февраля 2021 г.

\begin{abstract}
Представлены результаты исследования вольт-амперных характеристик светодиодных гетероструктур с активной областью на основе твердых растворов InAsSb и квантовых ям (КЯ) InAsSb/InAs, InAsSb/InAsSbP в интервале температур 4.2-300 K. Определены механизмы протекания тока в зависимости от температуры и параметров слоев гетероструктуры. Показано, что при температурах, близких к $300 \mathrm{~K}$, ток обусловлен диффузионным и рекомбинационным механизмами, в интервале температур $4.2-77 \mathrm{~K}$ оказывается существенным вклад туннельного механизма. Для гетероструктуры InAs/InAs/InAs ${ }_{0.15} \mathrm{Sb}_{0.31} \mathrm{P}_{0.54}$ установлено возникновение дополнительного канала протекания тока. Показано, что введение $108 \mathrm{KЯ} \mathrm{InAs} \mathrm{I}_{0.88} \mathrm{Sb}_{0.12} / \mathrm{InAs}_{\mathrm{s}}$ в активную область гетероструктуры приводит к увеличению токов утечки через гетеропереход во всем рассмотренном диапазоне температур, что, вероятно, связано с туннелированием носителей заряда.
\end{abstract}

Ключевые слова: гетероструктуры, арсенид индия, антимониды, вольт-амперные характеристики.

DOI: 10.21883/FTP.2021.06.50917.9622

\section{1. Введение}

Гетероструктуры (ГС) на основе узкозонных соединений $\mathrm{A}^{\mathrm{III}} \mathrm{B}^{\mathrm{V}}$ широко используются для создания светои фотодиодов, перекрывающих спектральную область, в которой находятся полосы поглощения природных и промышленных газов (длины волн 2-6 мкм). Данные ГС используются для изготовления детекторов теплового излучения [1,2], систем экологического мониторинга, медицинской диагностики [3-5] и др. приборов. Актуальным направлением исследований является оптимизация ГС для улучшения характеристик оптоэлектронных приборов на их основе. В этом отношении информативным является исследование как оптических, так и электрических свойств, в частности изучение вольтамперных характеристик (BAX). К настоящему времени уже имеется ряд работ, посвященных исследованию BAX ГC, содержащих гетеропереходы InAs( $\mathrm{Sb}) / \mathrm{InAsSbP}$, при этом существенно различающихся величиной полученных параметров (см., например, [6-8]), кроме того, большинство работ ограничивается узким температурным диапазоном. В то же время анализ ВАХ диодной структуры при различных температурах позволяет определить электрические параметры, необходимые для ее сопряжения с последующим считывающим устройством, и дает важную информацию о качестве $p$ - $n$-перехода. При этом исследование различных типов ГС позволяет проследить поведение ВАХ при изменении конструкции активной области. В настоящей работе представлены результаты исследования ВАХ в интервале температур $4.2-300 \mathrm{~K}$ светодиодных ГС, излучающих в диапазоне 3.4-4.2 мкм, с активной областью на основе твердых растворов InAsSb и квантовых ям (КЯ) InAsSb/InAs, InAsSb/InAsSbP. Исследования спектральных характеристик ряда подобных структур были проведены ранее в работе [9].

\section{2. Методика эксперимента}

Гетероструктуры были получены методом газофазной эпитаксии из металлоорганических соединений (МОГФЭ) на подложках InAs в компании Микросенcop Технолоджи. Были использованы подложки, легированные донорной примесью (серой) до концентрации электронов $n \approx 2 \cdot 10^{18} \mathrm{~cm}^{-3}$. Нелегированный активный слой ГС $n$-типа проводимости был изготовлен из эпитаксиальных слоев твердых растворов $\operatorname{InAs}_{1-x} \mathrm{Sb}_{x}$ с мольной долей антимонида индия $x_{\mathrm{InSb}}=0$ (образец $\mathrm{A}$ ) и 0.07 (образец В), а также из 108 КЯ $\operatorname{InAs}_{0.88} \mathrm{Sb}_{0.12} / \mathrm{InAs}$ (образец C) и 16 KЯ $\operatorname{InAs}_{0.94} \mathrm{Sb}_{0.06} / \mathrm{InAs}_{0.78} \mathrm{Sb}_{0.07} \mathrm{P}_{0.15}$ (образец D). Типичная толщина активного слоя составляла $\sim 2.5$ мкм. Рост ГС завершался формированием широкозонного барьерного слоя из четверного твердого pacтвора InAsSbP, легированного акцепторной приме- 
Параметры исследованных гетероструктур

\begin{tabular}{c|c|c}
\hline Образец & Активный слой & Барьерный слой \\
\hline $\mathrm{A}$ & $\mathrm{InAs}$ & $\operatorname{InAs}_{0.15} \mathrm{Sb}_{0.31} \mathrm{P}_{0.54}$ \\
$\mathrm{~B}$ & $\operatorname{InAs}_{0.93} \mathrm{Sb}_{0.07}$ & $\operatorname{InAs}_{0.70} \mathrm{Sb}_{0.10} \mathrm{P}_{0.20}$ \\
$\mathrm{C}$ & $108 \mathrm{~K} \mathrm{InAs}_{0.88} \mathrm{Sb}_{0.12} / \mathrm{InAs}$ & $\operatorname{InAs}_{0.70} \mathrm{Sb}_{0.10} \mathrm{P}_{0.20}$ \\
$\mathrm{D}$ & $16 \mathrm{KЯ} \mathrm{InAs} \mathrm{Is}_{0.94} \mathrm{Sb}_{0.06} / \mathrm{InAs}_{0.78} \mathrm{Sb}_{0.07} \mathrm{P}_{0.15}$ & $\operatorname{InAs}_{0.40} \mathrm{Sb}_{0.20} \mathrm{P}_{0.40}$
\end{tabular}

сью (цинком) до концентрации дырок $p \approx 2 \cdot 10^{18} \mathrm{~cm}^{-3}$. Параметры исследованных ГС приведены в таблице.

На основе ГС методом стандартной фотолитографии и жидкостного химического травления были изготовлены светодиодные чипы размером $380 \times 380$ мкм. Формирование контактной системы на основе многослойной композиции $\mathrm{Cr}-\mathrm{Au}-\mathrm{Ni}-\mathrm{Au}$ осуществлялось к подложке $n$-InAs и $p$-слою InAsSbP. На подложке размещался кольцевой контакт шириной 35 мкм с внутренним диаметром 200 мкм, а на эпитаксиальной стороне ГС был сформирован сплошной контакт. Чипы монтировались на корпуса ТО-18.

Для измерений ВАХ использовалась электрическая цепь, содержащая генератор синусоидального напряжения (частота 100 Гц). Для измерения тока последовательно с образцом был включен нагрузочный резистор сопротивлением 1Ом. Запись ВАХ осуществлялась с шагом по температуре $10 \mathrm{~K}$ с помощью электронного двухканального осциллографа PCSU 1000, подключенного к персональному компьютеру.

\section{3. Результаты и обсуждение}

На рис. 1 представлены ВАХ светодиодных ГС, записанные при их нагревании от 4.2 до $300 \mathrm{~K}$. Для всех исследуемых структур ВАХ имела вид диодной зависимости тока $I$ от приложенного смещения $U$. Рассмотрим BAX при прямом смещении. На начальных участках прямых ветвей наблюдается экспоненциальный рост $I(U)$ в интервале от 0 до $240-400 \mathrm{MB}(T=4.2 \mathrm{~K})$ и до $60-180 \mathrm{мB}(T=300 \mathrm{~K})$ в зависимости от типа ГС. При дальнейшем увеличении прямого смещения зависимость $I(U)$ становится линейной для всех исследуемых ГС. Как видно из рис. 1, увеличение температуры в диапазоне $4.2-300 \mathrm{~K}$ приводит к сдвигу прямой ветви ВАХ влево вследствие уменьшения высоты потенциального барьера. Характерной особенностью, присущей всем исследуемым ГС, является слабый температурный сдвиг прямой ветви BAX при изменении температуры в диапазоне $4.2-77 \mathrm{~K}$. Это указывает на преобладание процессов туннелирования носителей заряда, так как прохождение поверх барьеров и генерация в слое объемного заряда при низких температурах маловероятны. Наблюдаемое на рис. 1 температурное смещение обратных ветвей BAX всех ГС (кроме C) характерно для туннельного пробоя. Кроме того, в ВАХ не наблюдалось тока насыщения с увеличением обратного смещения. Из рис. 1 видно, что в области обратных смещений наблюдается близкая к квадратичной зависимость $I(U)$ начиная со значений $\sim 160$ и $\sim 50$ мВ для гетероструктур А и С соответственно, при этом вид зависимости практически не меняется с увеличением температуры. Такое поведение BAX ранее наблюдалось для изотипных гетеропереходов II типа $n$-InAs $/ n-\mathrm{InAsSbP}$ и $n-\mathrm{Si} / n-\mathrm{Ge}[10,11]$.

Для линейных участков BAX при больших прямых токах определялось напряжение отсечки $U_{c o}$, характеризующее величину потенциального барьера для носителей заряда, путем аппроксимации прямой ветви функцией вида

$$
I=\left(U-U_{c o}\right) / R_{s},
$$

где $R_{s}$ - последовательное дифференциальное сопротивление, определенное из линейного участка прямой ветви BAX как $d U / d I$.

$\mathrm{C}$ увеличением содержания InSb в активной области от 0 до 0.07 величина $U_{\text {co }}$ убывает от $0.138 \mathrm{~B}$ (образец А) до $0.112 \mathrm{~B}$ (образец В) при $T=300 \mathrm{~K}$, что соответствует уменьшению ширины запрещенной зоны $E_{g}$ твердого раствора InAsSb [9]. Для всех исследуемых ГС характерно монотонное убывание величины $U_{c o}$ с ростом температуры. В то же время величины $U_{c o}$ были меньше значений $E_{g}$ соответствующего материала активной области ГС. Относительно низкое значение $U_{c o}$, повидимому, отражает существенный вклад токов утечки в механизм переноса заряда, обусловленных свойствами узкозонных соединений $\mathrm{A}^{\mathrm{III}} \mathrm{B}^{\mathrm{V}}$. Для структуры $\mathrm{A}$ при $T=300 \mathrm{~K}$ величина $U_{c o}$ показывает существование барьера $\sim 0.138 \mathrm{~B}$, что в 2.5 раза меньше величины $E_{g}$ активной области InAs (0.35 эB) (рис. 2). Данная особенность ВАХ, вероятнее всего, связана с присутствием токов утечки через гетерограницу $\mathrm{InAs} / \mathrm{InAs}_{0.15} \mathrm{Sb}_{0.31} \mathrm{P}_{0.54}$.

Особый интерес представляют ВАХ структур В и С. Данные ГС имели одинаковые барьерные слои из $\mathrm{InAs}_{0.70} \mathrm{Sb}_{0.10} \mathrm{P}_{0.20}$, но различались конструкцией активной области (см. таблицу). Ранее было установлено, что введение КЯ в активную область структур не только приводит к ожидаемому (с учетом изменения ее химического состава) смещению максимума спектра электролюминесценции, но и к существенному увеличению его полуширины, с 400 до 800 нм при $T=300 \mathrm{~K}$ [9]. Из рис. $1, b$ видно, что наличие $108 \mathrm{KЯ}$ $\operatorname{InAs}_{0.88} \mathrm{Sb}_{0.12} / \mathrm{InAs}$ в активном слое привело и к изменению вида ВАХ по отношению к ВАХ немодифицированного $p-n$-перехода, без квантовых ям. Следует отметить, что в ГС с 108 КЯ происходило двукратное 

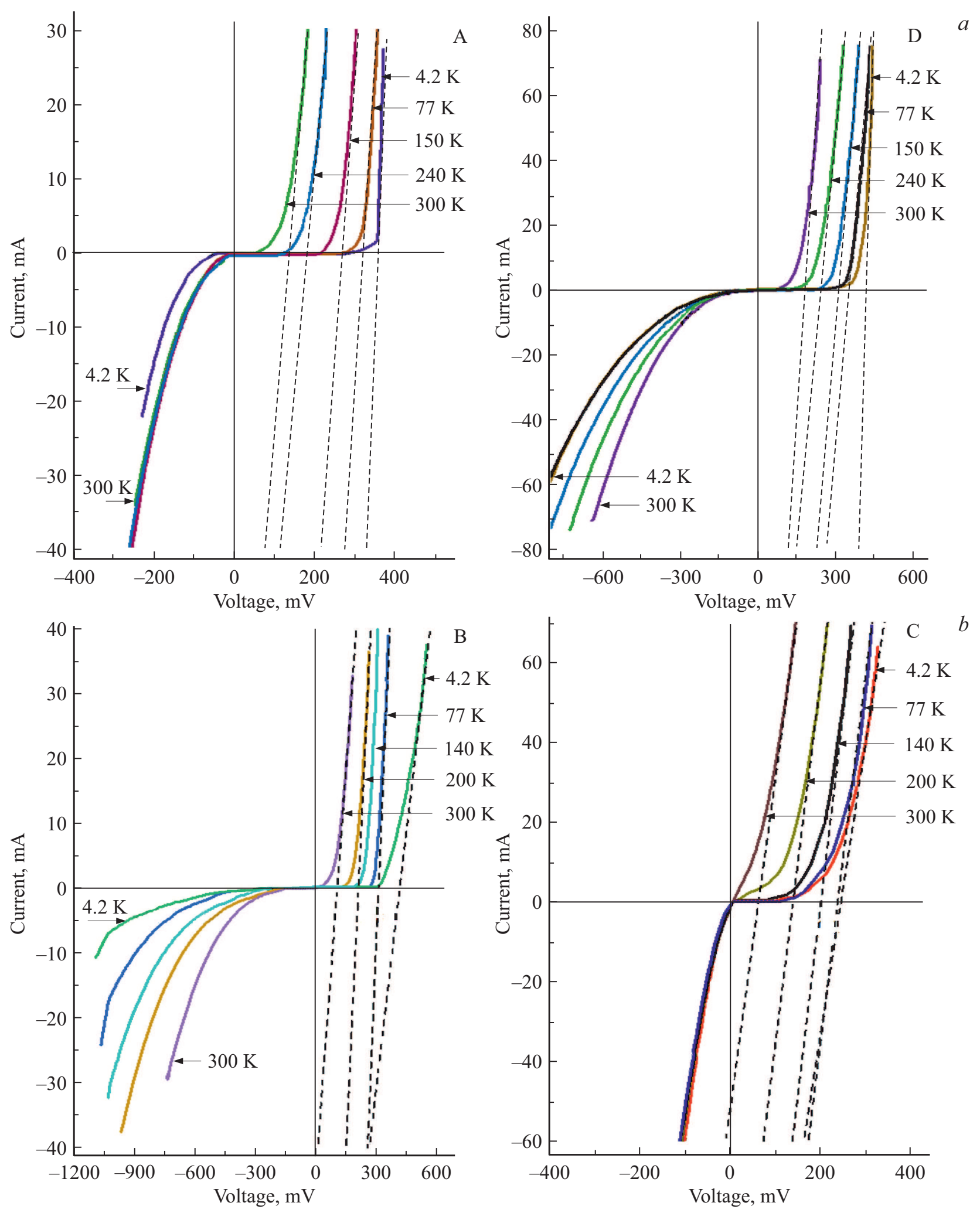

Рис. 1. Вольт-амперные характеристики образцов гетероструктур А и $\mathrm{D}(a)$, В и C $(b)$ при различных температурах. Штриховые линии - аппроксимация прямых ветвей ВАХ функцией вида (1).

уменьшение последовательного сопротивления относительно ГС В: при $T=4.2 \mathrm{~K} R_{S}$ имело значения 1.44 и 3.63 Ом, а при $T=300 \mathrm{~K}-1.17$ и 2.27 Ом для структур С и В соответственно. В результате включения 108 КЯ InAs ${ }_{0.88} \mathrm{Sb}_{0.12} / \mathrm{InAs}$ в активную область структуры C наблюдалось значительное увеличение тока при обрат- 


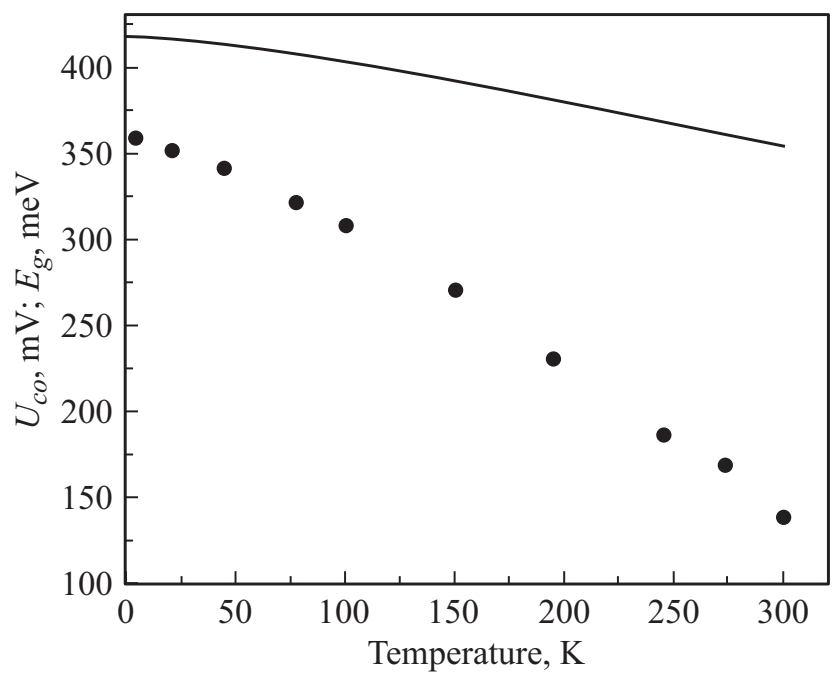

Рис. 2. Температурные зависимости напряжения отсечки прямых ветвей BAX гетероструктуры А (символы) и ширины запрещенной зоны InAs (линия).

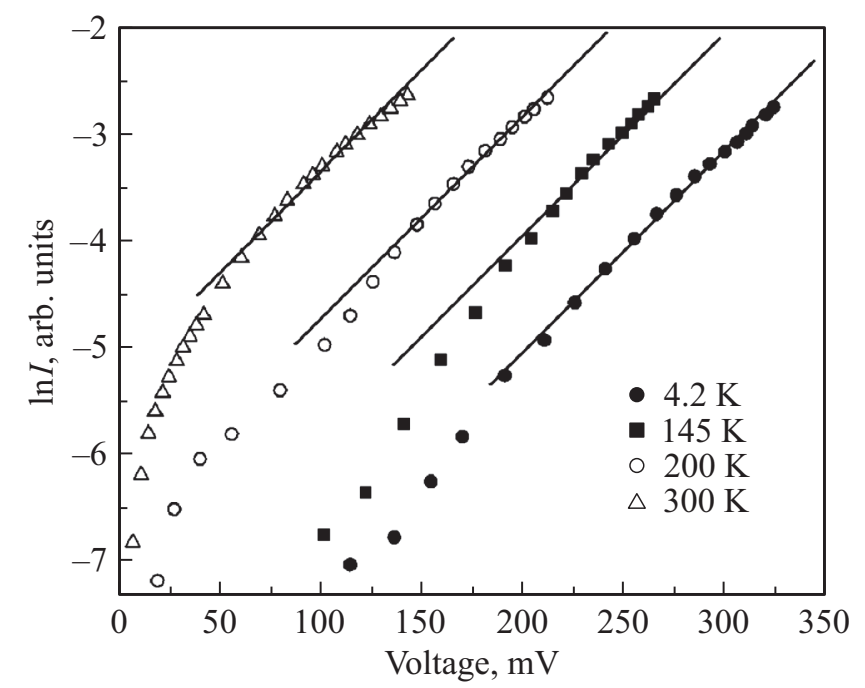

Рис. 3. Вольт-амперные характеристики образца С при различных температурах.

ном смещении. Кроме того, отсутствовала характерная для структуры В температурная зависимость тока при обратном смещении во всем диапазоне температур, что говорит о преобладании туннельного механизма тока. Для ГС с 16 КЯ $\operatorname{InAs}_{0.94} \mathrm{Sb}_{0.06} / \mathrm{InAs}_{0.78} \mathrm{Sb}_{0.07} \mathrm{P}_{0.15}$ в активной области эти эффекты не наблюдались.

Проведем оценку фактора идеальности $(\eta)$ ВАХ. Известно, что в идеальном $p-n$-переходе в случае, когда $\eta=1$, преобладает диффузионный ток, а если $\eta=2$, доминирует ток, обусловленный рекомбинацией в слое объемного заряда [12]. Согласно работе [13], при $T>200 \mathrm{~K}$ в $p-n$-переходах на основе InAs и родственных ему твердых растворах преобладает диффузионный механизм тока, т. е., согласно теории Шокли,
ВАХ определяет рекомбинация в $n$ - и $p$-областях $p-n$ перехода. Как известно, при малых напряжениях на диоде, $U<E_{g} / e$, прямой ток описывается соотношением

$$
I \propto \exp \left(\frac{e U}{\eta k T}\right),
$$

где $e-$ заряд электрона, $k-$ постоянная Больцмана. В исследуемых ГС при $T=300 \mathrm{~K}$ фактор идеальности принимал значения в диапазоне от 1.03 до 1.45 в области малых значений напряжения на диоде, что свидетельствует о смешанном механизме переноса заряда, вклад вносили как диффузионная, так и рекомбинационная составляющие. При низких температурах $(4.2-77 \mathrm{~K})$ были получены более высокие значения параметра $\eta$. Для образца В фактор идеальности принимал значения 2.14 и 9.75 при температурах 77 и $4.2 \mathrm{~K}$ соответственно. Более высокое значение $\eta$ указывает на вклад туннельного эффекта в области низких температур. На рис. 3 представлены BAX гетероструктуры С в полулогарифмическом масштабе при различных температурах. Видно, что при достаточно большом напряжении смещения $\ln I$ линейно увеличивается с ростом напряжения, однако наклон данной зависимости практически не меняется с ростом температуры образца, что позволяет сделать предположение о туннельной природе тока. Согласно работе [14], наблюдаемая зависимость $\ln I(U)$ характерна для туннельно-рекомбинационной модели, и линейные участки BAX можно описать функцией вида

$$
I \sim \exp (A V) \exp (B T),
$$

где $A$ и $B-$ константы.

Анализ полученных прямых ветвей ВАХ показал, что величина $d \ln I / d U$ практически не менялась с ростом температуры $\left(A=19\right.$ и $17.7 \mathrm{~B}^{-1}$ при $T=4.2$ и $300 \mathrm{~K}$ соответственно). В связи с этим можно сделать вывод, что при некотором достаточно большом смещении диффузионная составляющая тока полностью исчезала, и ток определялся туннельным механизмом. Преобладание туннелирования носителей заряда подтверждает также постоянство величины $d \ln I / d T$, которая в рассматриваемом диапазоне температур имела значение $\sim 9 \cdot 10^{-3} \mathrm{~K}^{-1}$.

\section{4. Заключение}

В работе представлены результаты исследования вольт-амперных характеристик светодиодных гетероструктур с активной областью на основе твердых растворов InAsSb и квантовых ям InAsSb/InAs и InAsSb/InAsSbP в интервале температур $4.2-300 \mathrm{~K}$. Проведена оценка последовательного сопротивления и напряжения отсечки прямых ветвей BAX. Определены механизмы протекания тока в зависимости от температуры и параметров гетероструктуры: при температурах, близких к $300 \mathrm{~K}$, перенос заряда обусловлен механизмами диффузии и рекомбинации, а в интервале температур 
4.2-77 K проявляется эффект туннелирования. Показано возникновение дополнительного канала протекания тока для гетероструктуры InAs/InAs/InAs ${ }_{0.15} \mathrm{Sb}_{0.31} \mathrm{P}_{0.54}$. Введение 108 КЯ $\mathrm{InAs}_{0.88} \mathrm{Sb}_{0.12} / \mathrm{InAs}$ в активную область гетероструктуры привело к увеличению токов утечки, вероятно, связанных с туннелированием носителей заряда. Таким образом, специфика конструкции активной области исследованных гетероструктур оказывает существенное влияние не только на их спектральные, но и на электрические характеристики, что необходимо учитывать при проектировании оптоэлектронных приборов среднего инфракрасного диапазона.

\section{Конфликт интересов}

Авторы заявляют, что у них нет конфликта интересов.

\section{Список литературы}

[1] D. Zymelka, B. Matveev, S. Aleksandrov, G. Sotnikova, G. Gavrilov, M. Saadaoui. Flex. Print. Electron., 2, 045006 (2017).

[2] G.Y. Sotnikova, S.E. Aleksandrov, G.A. Gavrilov. Proc. SPIE, 8073, 80731A (2011).

[3] D. Jung, S. Bank, M.L. Lee, D. Wasserman. J. Optics, 19, 123001 (2017).

[4] D.Z. Ting, A. Soibel, A. Khoshakhlagh, S.A. Keo, B. Rafol, A.M. Fisher, B.J. Pepper, E.M. Luong, C.J. Hill, S.D. Guhapala. Infr. Phys. Technol., 97, 210 (2019).

[5] P.N. Brunkov, N.D. Il'inscaya, S.A. Karandashev, A.A. Lavrov, B.A. Matveev, M.A. Remennyi, N.M. Stus', A.A. Usikova. Infr. Phys. Technol., 73, 232 (2015).

[6] С.А. Карандашев, Б.А. Матвеев, М.А. Ременный. ФТП, 53, 147 (2019).

[7] А.П. Астахова, А.С. Головин, Н.Д. Ильинская, К.В. Калинина, С.С. Кижаев, О.Ю. Серебренникова, Н.Д. Стоянов, Zs.J. Horvath, Ю.П. Яковлев. ФТП, 44, 278 (2010).

[8] A. Krier, M. Yin, A.R.J. Marshall, S.E. Krier. J. Electron. Mater., 45, 2826 (2016).

[9] K.D. Mynbaev, A.V. Shilyaev, A.A. Semakova, E.V. Bykhanova, N.L. Bazhenov. Opto-Electron. Rev., 25, 209 (2017).

[10] В.В. Романов, Э.В. Иванов, К.Д. Моисеев. ФТТ, 60, 585 (2018).

[11] А. Милнс, Д. Фойхт. Гетеропереходы $u$ переходы металл-полупроводник (М., Мир, 1975).

[12] В.В. Пасынков, Л.К. Чиркин. Полупроводниковые прибоpы (М., Высш. шк., 1987).

[13] A. Krier, Y. Mao. Infr. Phys. Technol., 38, 397 (1997).

[14] Б.Л. Шарма, Р.К. Пурохит. Полупроводниковые гетеропереходы (М., Сов. радио, 1979).

\section{Study of current-voltage characteristics of InAsSb-based LED heterostructures in $4.2-300 \mathrm{~K}$ temperature range}

\author{
A.A. Semakova ${ }^{1}$, N.L. Bazhenov ${ }^{2}$, K.D. Mynbaev ${ }^{2}$, \\ A.V. Chernyaev ${ }^{2,3,4}$, S.S. Kizhaev ${ }^{3}$, N.D. Stoyanov ${ }^{3}$ \\ 1 ITMO University, \\ 197101 St. Petersburg, Russia \\ ${ }^{2}$ loffe Institute, \\ 194021 St. Petersburg, Russia \\ ${ }^{3}$ Microsensor Technology, \\ 194223 St. Petersburg, Russia \\ ${ }^{4}$ Budyonny Military Academy of the Signal Corps, \\ 194064 St. Petersburg, Russia
}

\begin{abstract}
Results of the study of current-voltage characteristics of LED heterostructures with an active region based on InAsSb solid solutions and InAsSb/InAs or InAsSb/InAsSbP quantum wells (QWs) in the temperature range $4.2-300 \mathrm{~K}$ are presented. The carrier transport mechanisms depending on the temperature and the heterostructure design were determined. It is shown that the charge transport through the heterostructures is governed by diffusion and recombination mechanisms at the temperatures close to $300 \mathrm{~K}$; in the temperature range $4.2-77 \mathrm{~K}$, the contribution of the tunnelling mechanism was observed. For heterostructure InAs/InAs/InAs ${ }_{0.15} \mathrm{Sb}_{0.31} \mathrm{P}_{0.54}$ the additional channel of the carrier transport was evolved. It was shown that the presence of $108 \mathrm{QWs}$ In $\mathrm{As}_{0.88} \mathrm{Sb}_{0.12} / \mathrm{InAs}$ into the active region led to an increase in the leakage currents through the heterojunction in the whole temperature range, which is probably related to tunnelling of charge carriers.
\end{abstract}

